\section{Commentary: Are coronary aneurysms surgical disease?}

\author{
Yuji Kaku, MD, Jacob Kriegel, MD, and \\ Hiroo Takayama, MD, PhD
}

Because the available surgical knowledge and the contemporary guidelines are limited with respect to aneurysmal coronary diseases, this case report provides an excellent opportunity to learn more about this entity. Although we typically encounter coronary aneurysms in a mild-to-moderate (ie, ectatic) form accompanying stenotic coronary disease for coronary artery bypass grafting consultations without a need of aneurysm repair, larger aneurysms may require interventions. The key surgical principles are aneurysm exclusion and distal bypass.

Aneurysmal exclusion with inflow and outflow ligation can be challenging. In the present case, the authors performed the proximal occlusion by pericardial patch closure of the left main ostium; however, residual flow within the excluded aneurysm was noted. ${ }^{1}$ Incising the aneurysm provides excellent access to potential sites of inflow, although the calcified nature of the presented aneurysms might have prohibited this approach.

Total arterial revascularization to the distal arteries, as done in this case, may provide long-term survival benefit. ${ }^{1}$ Especially in pediatric cases, arterial grafting should be considered to further accommodate somatic growth. ${ }^{2}$ If ligation of a mild or moderate aneurysmal proximal artery is not performed, saphenous vein grafting may be a choice to overcome competitive flow.

Adding to the excellent discussion in this article, the literature suggests that coronary fistulas could be a cause of aneurysm formation due to persistent high flow in the coronaries. ${ }^{3}$ This condition is most often congenital, although it

From the Division of Cardiac, Thoracic, and Vascular Surgery, Department of Surgery, Columbia University Medical Center/New York-Presbyterian, New York, NY.

Disclosures: The authors reported no conflicts of interest.

The Journal policy requires editors and reviewers to disclose conflicts of interest and to decline handling or reviewing manuscripts for which they may have a conflict of interest. The editors and reviewers of this article have no conflicts of interest.

Received for publication June 14, 2021; revisions received June 14, 2021; accepted for publication June 28, 2021; available ahead of print July 1, 2021.

Address for reprints: Hiroo Takayama, MD, PhD, Columbia University Medical Center, 177 Fort Washington Ave, New York, NY 10032 (E-mail: ht2225@cumc. columbia.edu).

JTCVS Techniques 2021;9:80-1

2666-2507

Copyright (C) 2021 The Author(s). Published by Elsevier Inc. on behalf of The American Association for Thoracic Surgery. This is an open access article under the CC BY-NC-ND license (http://creativecommons.org/licenses/by-nc-nd/4.0/).

https://doi.org/10.1016/j.xjtc.2021.06.033

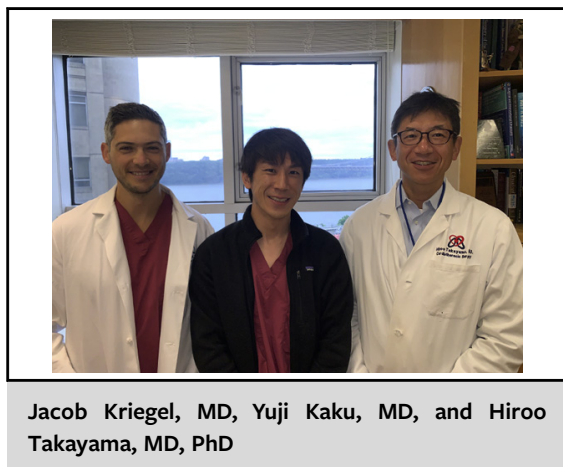

CENTRAL MESSAGE

Regarding coronary artery aneu-

rysms, much remains unknown.

Surgical studies are needed to

better define the role of their

surgical management.

can be acquired from trauma, infection, or iatrogenic injury or even be the consequence of aneurysms. ${ }^{4}$ Identifying the communication between artery and other systems, such as atria, ventricle, and pulmonary artery, is critical in surgical planning.

Finally, this unique and excellent case presentation reminds us of the need for a true coronary subspecialty as has recently been advocated by multiple groups. ${ }^{5,6}$ There are more questions than answers. What is the size threshold to repair a coronary aneurysm? What is the risk of unrepaired right coronary aneurysms or residual flow within the aneurysm after a repair? What is the benefit of the second and third arterial grafts? Complex cases such as this highlight the need for deep expertise among surgeons, development and application of novel techniques, and dedicated research efforts to explore best practices for atypical or rare presentation of coronary disease. In a recent review article on the management of coronary artery aneurysms, only 75 words were given for "surgical interventions" with the conclusion that "the precise success rate of these techniques is not known due to the rarity of this surgery and the impact of reporting bias." ${ }^{77} \mathrm{We}$ can do better.

\section{References}

1. Vo TX, Ngu JMC, Glineur D. Total arterial coronary artery bypass grafting of multiple coronary aneurysms. J Thorac Cardiovasc Surg Tech. 2021;9:73-7.

2. Ochi M. Review: surgical treatment of giant coronary aneurysms in pediatric patients with Kawasaki disease. Gen Thorac Cardiovasc Surg. 2018;66:121-9.

3. Steinberg I, Baldwin JS, Dotter CT. Coronary arteriovenous fistula. Circulation. 1958; 17:372-90.

4. Mangukia CV. Coronary artery fistula. Ann Thorac Surg. 2012;93:2084-92.

5. Mack M, Taggart D. Coronary revascularization should be a subspecialty focus in cardiac surgery. J Thorac Cardiovasc Surg. 2019;157:945-7. 
6. Rosati CM, Torregrossa G, Balkhy HH, Puskas JD. Dedicated training in advanced coronary surgery: need and opportunity. J Thorac Cardiovasc Surg. 2021;161: 2130-4.
7. Kawsara A, Nunez Gil IJ, Alqahtani F, Moreland J, Rihal CS, Alkhouli M. Management of coronary artery aneurysms. JACC Cardiovasc Interv. 2018;11: 1211-23. 